\title{
Relationship between quality of professional life and organizational commitment in intensive care unit nurses
}

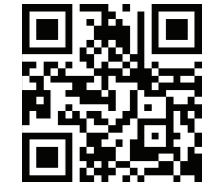

Original article

\author{
Mahboobeh Magharei ${ }^{a}$, Zinat Mohebbia,*, Soheila Jafari ${ }^{b}$ \\ ${ }^{a}$ Department of Nursing, School of Nursing and Midwifery, Shiraz University of Medical Sciences, Shiraz, Iran \\ ${ }^{b}$ Student Research Committee, Shiraz University of Medical Sciences, Shiraz, Iran
}

Received: 9 February 2021; Accepted: 8 April 2021; Published: 20 December 2021

\begin{abstract}
Objective: The quality of professional life has attracted the attention of many managers owing to its importance, and organizational commitment differs according to work conditions in an organization. As the largest professional group in the healthcare system, nurses face many stressful factors that can endanger their quality of professional life and organizational commitment. Despite their huge importance, these 2 variables have rarely been addressed or evaluated in the nursing profession. The present study was conducted to determine the relationship between quality of professional life and organizational commitment in nurses working in the intensive care units (ICUs) and critical care units (CCUs).

Methods: The present descriptive-analytical study was conducted on 221 nurses working in the ICUs of hospitals affiliated to Shiraz University of Medical Sciences and selected through proportional stratified sampling. The data collection tools comprised demographic questionnaires, the quality of work-life questionnaire by Walton with 8 dimensions, and the valid and reliable organizational commitment scale by Meyer and Allen. The data were analyzed in SPSS, version 23 (IBM Corporation, Armonk, New York, United States), using descriptive and inferential statistical techniques, including Spearman correlation, Pearson correlation, the Kruskal-Wallis test, the Mann-Whitney $U$ test, the $\chi^{2}$ test, and the independent $t$ test. $P<0.050$ was set as the level of statistical significance.

Results: The mean scores of quality of professional life and organizational commitment were $58.996 \pm 14.427$ and $93.840 \pm 13.900$, respectively, in the ICU nurses. The Pearson test showed positive and significant relationships between quality of professional life and organizational commitment $(r=0.392, P<0.001)$.

Conclusions: Given the positive relationship found in the present study between organizational commitment and quality of professiona life, it is recommended that organizational commitment be modified to improve the quality of professional life in nurses.
\end{abstract}

Keywords: quality of professional life $\bullet$ organizational commitment $\bullet$ nurses $\bullet$ ICU $・$ CCU

(c) Shanxi Medical Periodical Press.

\section{Introduction}

Healthcare organizations hold a special position in the community owing to their key role in disease prevention, care, and treatment. ${ }^{1}$ As a key component of the health system, hospitals seek to optimally use resources, given the increasing costs and scarcity of resources. ${ }^{2}$ Nurses play a major role in sensitive hospital wards

How to cite this article: Magharei M, Mohebbi Z, Jafari S. Relationship between quality of professional life and organizational commitment in intensive care unit nurses. Front Nurs. 2021;4:399-406.

* Corresponding author.

E-mail:mohebbi04@yahoo.com (Z. Mohebbi).

Ә Open Access. (c) 2021 Magharei et al., published by Sciendo. (cc) BY Attribution 4.0 License. 
such as intensive care units (ICUs), which are equipped with state-of-the-art technologies and facilities required for the care of critically ill patients. ${ }^{3}$ Being in a lifethreatening condition, patients in ICUs need continuous monitoring by specialists and trained nurses for diagnosis, management, and care. These nurses should have ample knowledge of physiological warning signs and be able to appropriately respond to rapid changes in patient status. ${ }^{3}$ Empowering nurses as an important human resource of hospitals reduces occupational stress and promotes organizational commitment and trust, productivity, participation in decision-making, quality care, patient satisfaction, self-sufficiency, a sense of independence, self-confidence, accountability, and ultimately organizational effectiveness. Moreover, levels of job satisfaction, motivation, and organizational loyalty are higher in empowered staff in such a way that they tend to involve themselves more in achieving organizational goals. ${ }^{4}$

Human resources are considered the most valuable asset in organizations. Paying attention to the needs of the staff and their psychophysical health and improving the quality of their professional life is therefore crucial for increasing the productivity and efficiency of organizations. ${ }^{5}$ Quality of professional life refers to actual work conditions in an organization such as wages and benefits, welfare facilities, health and safety measures, participation in decision-making, and work management methods. The perception of staff of their job is specifically explained by the quality of professional life,${ }^{6}$ which is evaluated as a criterion for occupational performance according to their psychosocial characteristics and the degree to which they adapt to work conditions. ${ }^{7}$ High quality of professional life is essential for organizations that prioritize recruiting and retaining their personnel. On the other hand, poor quality of professional life is a major problem that affects all the personnel irrespective of their position and situation and indirectly damages their morale and increases their absenteeism, desertion, and mental stress by causing fatigue and job dissatisfaction. ${ }^{8}$

With a sublime position in organizational behaviors, organizational commitment refers to the strong desire of a member to remain in the organization, their tremendous efforts to achieve organizational goals, and their firm belief in organizational values and objectives. ${ }^{9}$ According to Cohen, high organizational commitment results in useful outcomes, including enhanced performance effectiveness and productivity and reduced desire for desertion and absenteeism at individual and organizational levels. ${ }^{10}$ Identifying the factors and features that improve commitment, therefore, appears worthwhile for organizations. ${ }^{11}$ The organizational factors that improve organizational commitment include the high quality of professional life and job security. ${ }^{12}$ Increasing commitment and accountability in human resources is particularly important in health organizations, as the clients of these organizations themselves constitute the human resources of other organizations. ${ }^{13}$ At the forefront of health care, nurses not only should provide excellent levels of patient care but also should have to play an active role in proceeding with major organizational tasks. ${ }^{14}$ Having the perception that the organization has adequately contributed to their support and welfare helps nurses work effectively and make greater efforts to cope with stressful circumstances. Benefiting from factors such as industry-standard salaries, proper retirement plans, frequent merit-based promotions, greater availability of leave, and rewards for exceeding established standards of performance improves organizational commitment and the desire to stay. ${ }^{15}$

The heavy workload of ICU nurses associated with psychophysical pressure is caused by taking care of critically ill patients, working shifts, their high number of working hours, a lack of auxiliary workforce, and using advanced care equipment.

Given the effect of the heavy workload on quality of professional life and organizational commitment in ICU nurses and the failure to concurrently investigate these 2 variables in ICU and critical care unit (CCU) nurses in the literature, the present study was conducted to determine the relationship between quality of professional life and organizational commitment in ICU nurses and provide managers with the necessary support, counseling, and treatment.

\section{Methods}

The present descriptive, analytical, and cross-sectional study was conducted from 2018 to 2019 on a population comprising 530 clinical staff working in adult ICUs and CCUs of 3 hospitals affiliated to Shiraz University of Medical Sciences. The sample size, based on the findings of the study of Mehdad et al, ${ }^{16}$ was calculated as 221 in MedCalc (MD Aware, LLC, New York, United States)with a $90 \%$ test power and a $5 \%$ alpha error. Structural equation modeling was used to explain the relationships among the variables. The sample size in each hospital was then determined using proportional to size cluster sampling. The inclusion criteria comprised willingness to participate in the study, having a minimum of bachelor's degree in nursing, having $>1$ year of work experience in ICUs, and being a clinical nurse rather than a manager.

The data were collected using the following three questionnaires: 
(1) Demographic questionnaire: The study subjects completed this questionnaire, which comprised personal and occupational details, including age, gender, level of education (from bachelor to $\mathrm{PhD}$ ), type of CCUs or ICUs, the number of shifts per week, type of employment, years of work experience, amount of income, marital status, the number of children, and type of residence (personal, tenant, and so on). This questionnaire was developed according to previous studies and expert comments.

(2) The quality of work-life questionnaire based on an 8-component model was proposed by Walton: This 27-item questionnaire was used to measure 8 dimensions, i.e., adequate and fair compensation, safe and healthy working environment, providing an opportunity for continued growth and security, constitutionalism in the organization, the social relevance of work-life, total life span, social unity, and integration and development of human capabilities. The items were scored on a 5-point Likert scale ranging from 1 (very low) to 5 (very high) [8] with scores of $27-45,46-90$, and more than 91 suggesting the poor quality, moderate quality, and high quality of professional life, respectively. ${ }^{17}$ In 1973, Walton ${ }^{18}$ confirmed the construct validity of this questionnaire by calculating a coefficient value of 0.780 and its reliability by calculating a Cronbach alpha value of 0.850 . Hadizadeh Talasaz et $\mathrm{al}^{19}$ also confirmed the validity of this questionnaire by reporting an internal consistency coefficient value of 0.920 and its reliability by calculating a Cronbach alpha value of 0.830 .

(3) The organizational commitment scale: This 24-item questionnaire was introduced by Allen and Meyer ${ }^{20}$ in 1990, which comprised 3 dimensions, i.e., affective commitment, continuance commitment, and normative commitment. The items were scored on a 7-point Likert scale ranging from 7 (completely agree) to 1 (completely disagree), with higher scores denoting higher commitment and the total score being 24-168. ${ }^{20,21}$ A total score of 24-72, 73-121, and 122-168 showed low commitment, moderate commitment, and high commitment, respetively. ${ }^{22}$ In 1990, Allen and Meyer ${ }^{20}$ determined a reliability coefficient value of 0.870 for affective commitment, 0.750 for continuance commitment, and 0.790 for normative commitment. Moreover, Makarem et al. ${ }^{23}$ confirmed the face and content validity of this scale, as well as its reliability, by calculating a Cronbach alpha value of 0.706 .
The data collected were analyzed in SPSS, version24 (IBM Corp. Released 2016. IBM SPSS Statistics for Windows, version 24.0. Armonk, NY: IBM Corp.), using descriptive statistics, including relative frequency, frequency and mean, and inferential statistics such as the independent $t$ test, Analysis of Variance (ANOVA), and the Pearson correlation coefficient. The level of statistical significance was set as $P<0.050$ and the confidence interval as $95 \%$. The Kolmogorov-Smirnov test was also performed before conducting the statistical tests to investigate the distribution normality of the data.

\section{Results}

The mean age of the 221 participating nurses was $30.630 \pm 5.140$ years, their mean work experience was $6.900 \pm 5.240$ years, and most of them had a monthly salary of $30 \pm 0.41$ million Iranian rial (IRR). Moreover, $76.90 \%$ of them were women, $52 \%$ married, $71 \%$ childless, $49.30 \%$ tenants, and $28.50 \%$ officially employed, while $88.20 \%$ had a bachelor's degree and $93.20 \%$ worked shifts. More than $70 \%$ of the nurses also worked 7-8 shifts a week (Table 1).

According to Table 2, the total mean score of quality of professional life was $58.990 \pm 14.420$ in the nurses and that score was high in $35(15.80 \%)$, moderate in $184(83.30 \%)$, and low in $2(0.90 \%)$ nurses. According to Table 3, the total mean score of organizational commitment was $93.840 \pm 13.900$ and this score was high in $11(5 \%)$, moderate in $200(90.50 \%)$, and low in 10 $(4.50 \%)$ nurses.

The present study found that the main study variables, i.e., quality of professional life and organizational commitment, are not associated with age, gender, level of education, number of shifts, type of shift, number of children, type of residence, type of employment, and work experience. Significant relationships were, however, observed between the type of unit and quality of professional life $(P=0.030)$. Table 2 presents the mean scores of quality of professional life and its dimensions, with the development of human capabilities receiving the highest score of $9.390 \pm 3.100$ and adequate and fair compensation receiving the lowest score of $5.480 \pm 1.800$. The mean score of quality of professional life, obtained as $58.990 \pm 14.420$, was also categorized as moderate (Table 2).

According to Table 3, normative commitment received the lowest score and continuance commitment received the highest score. The score of organizational commitment with a mean of $93.840 \pm 13.900$ was also moderate.

The Pearson test showed positive and significant relationships between quality of professional life and organizational commitment $(r=0.39, P<0.001)$ (Table 4). 


\begin{tabular}{|c|c|c|c|}
\hline \multirow{2}{*}{ Demographic factor } & \multirow{2}{*}{ Percent (\%) } & \multicolumn{2}{|c|}{$P$ value } \\
\hline & & Quality of professional life & Organizational commitment \\
\hline Gender & & 0.963 & 0.501 \\
\hline Female & 76.9 & & \\
\hline Male & 23.1 & & \\
\hline Level of education & & 0.229 & 0.097 \\
\hline Bachelor & 88.2 & & \\
\hline Master + Master's student & 11.3 & & \\
\hline $\mathrm{PhD}+\mathrm{PhD}$ student & 0.5 & & \\
\hline Type of unit & & 0.035 & 0.063 \\
\hline Internal ICU & 18.6 & & \\
\hline Surgical ICU & 17.6 & & \\
\hline Neurosurgery ICU & 21.7 & & \\
\hline Emergency ICU & 7.2 & & \\
\hline Cardiac surgery ICU & 11.8 & & \\
\hline ICU general & 17.2 & & \\
\hline ICU central & 5.9 & & \\
\hline Number of shifts per week & & 0.409 & 0.629 \\
\hline 5 and 6 & 14.1 & & \\
\hline 7 & 36.2 & & \\
\hline 8 & 35.7 & & \\
\hline 9 & 14 & & \\
\hline Type of employment & & 0.650 & 0.264 \\
\hline Official & 28.5 & & \\
\hline Contractual & 11.3 & & \\
\hline Conventional & 14.5 & & \\
\hline Company & 17.6 & & \\
\hline Projective & 28.1 & & \\
\hline Marital status & & 0.426 & 0.599 \\
\hline Married & 52 & & \\
\hline Single & 48 & & \\
\hline Number of children & & 0.153 & 0.125 \\
\hline 0 & 71 & & \\
\hline 1 & 21.7 & & \\
\hline 2 & 7.2 & & \\
\hline Type of residence & & 0.390 & 0.269 \\
\hline Personal & 42.1 & & \\
\hline Tenant & 49.3 & & \\
\hline Dorm & 8.6 & & \\
\hline
\end{tabular}

Note: ICU, intensive care unit.

Table 1. Frequency percentage of demographic variables and their relationship with quality of professional life and organizational commitment.

\section{Discussion}

The present study was conducted to determine the relationship between quality of professional life and organizational commitment in ICU and CCU nurses. The findings suggested moderate levels for quality of professional life in these nurses (total score $=58.990$ ), which is consistent with previous findings reported in the literature. ${ }^{6,8,9}$ Research conducted in Iran, such as a study by Bakhshi et al., ${ }^{8}$ also suggested the moderate quality of professional life in healthcare workers. Paying attention to the dimensions of quality of professional life 


\begin{tabular}{lccc}
\hline Variable & $\mathrm{M} \pm \mathrm{SD}$ & Min & Max \\
\hline \hline Fair compensation & $5.480 \pm 1.840$ & 3 & 12 \\
Safe environment & $6.450 \pm 2.130$ & 2 & 13 \\
$\begin{array}{l}\text { Opportunity for growth } \\
\text { Constitutionalism in the }\end{array}$ & $8.440 \pm 2.380$ & 1 & 13 \\
$\begin{array}{l}\text { organization } \\
\text { Social relevance }\end{array}$ & $6.700 \pm 2.290$ & 3 & 12 \\
$\begin{array}{l}\text { Total life space } \\
\text { Integration in the }\end{array}$ & $6.720 \pm 1.850$ & 3 & 11 \\
$\begin{array}{l}\text { organization } \\
\begin{array}{l}\text { Development of human } \\
\text { capabilities }\end{array}\end{array}$ & $9.360 \pm 2.960$ & 4 & 16 \\
$\begin{array}{l}\text { The total score of quality } \\
\text { of professional life (sum } \\
\text { of all the following factors) }\end{array}$ & $58.990 \pm 14.420$ & 27 & 101 \\
\hline
\end{tabular}

Note: M, mean; SD, standard deviation; ICUs, intensive care units.

Table 2. The mean score of quality of professional life and its dimensions in nurses of ICUs.

\begin{tabular}{lccc}
\hline Variable & $\mathrm{M} \pm \mathrm{SD}$ & Min & Max \\
\hline \hline Affective commitment & $31.270 \pm 7.900$ & 11 & 56 \\
Continuance commitment & $32.370 \pm 4.600$ & 17 & 47 \\
Normative commitment & $30.190 \pm 6.600$ & 14 & 50 \\
$\begin{array}{l}\text { Organizational commitment } \\
\text { (the sum of the three- }\end{array}$ & $93.840 \pm 13.900$ & 60 & 139 \\
dimensional scores) & & & \\
\hline
\end{tabular}

Note: M, mean; SD, standard deviation; ICUs, intensive care units.

Table 3. The mean score of organizational commitment and its dimensions in nurses of ICUs.

and the factors improving it is therefore crucial. Moreover, Kelbiso et al. ${ }^{24}$ found the quality of professional life to be low and moderate in the majority of participants and high in $32.80 \%$. Furthermore, Almalki et al. ${ }^{25}$ found the participants to be dissatisfied with their quality of professional life. These discrepancies in results can be explained by differences in organizational management in different countries and the financial status, workplace environment, and psychological characteristics of 2 different communities.

The present study found a high quality of professional life in $2(0.90 \%)$ of the nurses, which is almost consistent with the results obtained by Sakkaki et al. ${ }^{26}$, who reported a high quality of professional life in none of the 85 participants. This might have been caused by the exposure of ICU and CCU nurses to emergency and unexpected situations and high levels of workplace noise and timings of their shift works, long working hours, disproportionate salary to responsibility, heavy workload, and high stress levels, which can affect their perception of the quality of professional life.

\begin{tabular}{ccc}
\hline Items & Quality of professional life & Organizational commitment \\
\hline \hline$r$ & 1 & 0.392 \\
$P$ & & $<0.001$ \\
\hline
\end{tabular}

Note: ICUs, intensive care units.

Table 4. The relationship between quality of professional life and organizational commitment in nurses of ICUs (the Pearson test).

The present study reported moderate levels for organizational commitment (score $=93.840$ ), which is consistent with the majority of studies conducted in Iran and other countries. ${ }^{22,27,28}$ The poor organizational and occupational factors, including organizational justice, job satisfaction, job safety and security, organizational conflict, and burnout reported in the literature can justify the moderate organizational commitment in nurses in Iran. Improving organizational commitment is crucial, given its effect on the occupational performance of staff and that unfavorable organizational commitment is associated with consequences such as desertion by nurses, which can seriously disrupt hospital activities. ${ }^{22}$

The mean scores of dimensions of organizational commitment are $32.37 \%$ for continuance commitment, $31.27 \%$ for affective commitment, and $30.19 \%$ for normative commitment; it seems that continuance commitment is the best predictor of organizational commitment, followed by affective commitment and normative commitment. Continuance commitment suggests that employees accumulate capital in the organization, and the longer their stay in the organization, the more capital they can accumulate, which makes losing it costly. ${ }^{29}$ Continuance commitment, therefore, reflects the cost of leaving the organization versus the benefits of staying, and employees with continuance commitment are highly likely to avoid leaving their organization and joining a new organization as a result of comparing the investments and benefits of the new job with those of their current occupation. ${ }^{30}$ Normative commitment received the lowest score in the present study. Normative commitment refers to a sense of responsibility in employees for the investment made in them by the organization. Employees with normative commitment tend to remain committed and serve the organization unless their duties are discharged and they get legally and ethically relieved. ${ }^{30}$

The present study found the highest level of commitment in the staff to be associated with their continuance commitment, which is consistent with the results of a study by Abbaszadeh et al. in nurses. ${ }^{29}$ Veličković et al. ${ }^{31}$ found the score of affective commitment to be the highest in nurses in Serbia compared to that of other dimensions. Roohi et al. ${ }^{32}$ found the score of normative commitment to be the highest compared to the scores 
of other dimensions of organizational commitment, which is inconsistent with the present findings. Ebadi et al. ${ }^{33}$ and Delgoshaei et al. ${ }^{34}$ however, found affective commitment in nurses to receive the highest score compared to the scores of other dimensions of organizational commitment. These differences in organizational commitment can be attributed to personal, organizational, and non-organizational factors. Although effective commitment appears to emotionally link employees to the organization, continuance commitment is more effective in securing their commitment to the organization. Employees who observe that ethical values are observed in organizational decision-making are more willing to stay with their organization, especially when they feel their personal ethical values are compatible with those of the organization. ${ }^{29}$

The result of the present study shows positive and significant relationships between quality of professional life and organizational commitment, which is consistent with the findings obtained by Eren and Hisar, ${ }^{35}$ Zarei et al., ${ }^{9}$ Hadizadeh Talasaz et al., ${ }^{19}$ and Hashempour et al. ${ }^{36}$

The correlation between organizational commitment and quality of professional life suggests a mutual relationship between these variables in a way that increasing or decreasing either one, respectively, increases or decreases the other. The potentially significant effect of quality of professional life on organizational commitment in employees can result in certain favorable behaviors in the organization and increase efficiency and effectiveness. To improve attachment and commitment to the organization in their employees, organizational managers should therefore pay special attention to the quality of professional life and take measures to enhance it. On the other hand, the damage caused by failing to pay attention to organizational commitment makes employees find ways to satisfy their needs, which often contradicts collective interests, disrupts social relationships, and creates a vicious circle.

\section{Conclusions}

The findings of the present study indicated the presence of positive and significant correlations between quality of professional life and organizational commitment. Organizational managers are therefore recommended to adopt policies and measures in a way that their employees find their workplace more favorable and their commitment to the organization strengthened. These programs include providing support by the management, improving supervision, holding training sessions, observing organizational justice, making efforts for fair payments, and striking a balance between work and life through increasing availability of leave, providing recreational and sports facilities, and improving the physical condition of the workplace.

\section{Limitation}

The limitations of the present study included the potential bias in the responses of the nurses, which was caused by their spiritual status, and prevailed despite the fact that they were suitably briefed on the study objectives before distribution of the questionnaires. Furthermore, the potential effect of personal differences between the study subjects on their perception of the quality of professional life was beyond the researcher's control. Further studies are therefore recommended to be conducted using more accurate methods, such as semi-structured in-depth interviews through qualitative research, to investigate the quality of professional life and organizational commitment in nurses.

\section{Acknowledgments}

The present article was extracted from a master's thesis on Adult Critical Care Nursing by Soheila Jafari in the School of Nursing and Midwifery supervised by Mahbobeh Mogharei. This article is approved and financially supported by the Ethics Committee of Shiraz University of Medical Sciences on 28 March 2018 (code: 97-17144). The authors would like to express their gratitude to the authorities of the Deputy of Research of Shiraz University of Medical Sciences and the ICU nurses of teaching hospitals affiliated with this university for their cooperation.

\section{Ethical approval}

The study protocol was approved by the Ethics Committee of Shiraz University of Medical Sciences (code: 970108-17144), and the researcher presented to the study setting and made the necessary arrangements with the relevant authorities, then introduced himself to the participants, briefed them on the study objectives, ensured their right to withdraw from the study at their own discretion, obtained their written consent, and distributed the questionnaires among them.

\section{Conflicts of interest}

All contributing authors declare no conflicts of interest. 
1. Donoso LM, Demerouti E, Garrosa Hernandez E, Moreno-Jimenez B, Carmona Cobo I. Positive benefits of caring on nurses' motivation and well-being: A diary study about the role of emotional regulation abilities at work. Int J Nurs Stud. 2015;52:804-816.

2. Javadi M, Jafari M. Correlation between organizational commitment and productivity in staffs of Isfahan University of medical sciences teaching hospitals. Health Inf Manag. 2014;10:1044-1050.

3. Khoeiniha F, Sheikhi M, Shokati A, Mohammadpour A. Nurses' clinical performance assessment in critical care units in teaching and non-teaching hospitals in Qazvin city: Based on Synergy Model. JHPM. 2016;5:28-36.

4. Greasley K, Bryman A, Dainty A, Price A, Soetanto R, King N. Employee perceptions of empowerment. Empl Relat. 2005;27:354-368.

5. Nasiri-Ziba F, Bogheiri F. Mental health status of critical care nurses in teaching hospitals of Tehran. Iran J Cardiovasc Nurs. 2013;1:6-12.

6. Mohammadi M, Mozaffari N, Dadkhah B, Etebari Asl F, Etebari Asl Z. Study of work-related quality of life of nurses in Ardabil Province Hospitals. J Health Care. 2017;19:108-116.

7. Sinha C. Factors affecting quality of work life: Empirical evidence from Indian organizations. Aust J Bus Manage Res. 2012;1:31-40.

8. Bakhshi E, Kalantari R, Salimi N, Ezati F. Assessment of quality of work life and factors related to it based on the walton's model: a cross-sectional study in employment of health and treatment sectors in Islamabad City. J Health Field. 2019;6:13-19.

9. Zarei E, Ahmadi F, Danshkohan A, Ramezankhani A. The correlation between organizational commitment and the quality of working life among staff of Sarpolzahab health network. J Health Promot Manage. 2016;5:61-69.

10. Cohen A, Golan R. Predicting absenteeism and turnover intentions by past absenteeism and work attitudes: an empirical examination of female employees in long term nursing care facilities. Career Dev Int. 2007;12:416-432.

11. Shohoudi M, Gholami Z, Alizadeh L, Farajalahi R. Mediating role of spiritual leadership in the relationship between sport self-efficacy and professional commitment in physical education teachers. Q J Educ Sch Stud. 2014;2:58-79.

12. Toker S, Biron M. Job burnout and depression: Unraveling their temporal relationship and considering the role of physical activity. J Appl Psychol. 2012;97:699-710.
13. Hosseinian S, Majidi A, Habibi S. Effective intra-organizational factors on the organization commitments of the personnel of Tehran Metro Police Stations. Denesh e Entezami. 2007;9:9-25.

14. Atak M. A research on the relation between organizational commitment and learning organization. Afr J Bus Manag. 2011;5:5612-5616.

15. Siew P, Chitpakdee B, Chontawan R. Factors predicting organizational commitment among nurses in state hospitals, Malaysia. Int Med J Malaysia. 2011;10:21-28.

16. Mehdad A, Mahdavirad N, Golparvar M. Relationship between quality of work life dimensions with organizational commitment and its components. J Sco Psychol. 2011;6:41-53.

17. Bigelow H. The Relationship between Quality of Work Life and Job Satisfaction and Organizational Commitment of the Secondary School Secondary School Teachers in Robat Karim. Robat Karim: Kharazmi University; 2015.

18. Walton RE. Quality of work life: what is it? Sloan Manag Rev. 1973;15:11-21.

19. Hadizadeh Talasaz Z, Nourani Saadoldin S, Shakeri M. Relationship between components of quality of work life with job satisfaction among midwives in Mashhad, 2014. Hayat. 2015;21:56-67.

20. Allen NJ, Meyer JP. The measurement and antecedents of affective, continuance and normative commitment to the organization. J Occup Psychol. 1990;63:1-18.

21. Boyokzadeh F, Vanaki Z, Asareh M. Reflection of emotional intelligence's nurse managers on nurses' organizational commitment. Q J Nurs Manage. 2017;6:42-52.

22. Khodadadei N, Salehi S. Relationship between organizational commitment and nurses' clinical competency. Q J Nurs Manag. 2018;7:18-28.

23. Makarem A, Jorbonyan A, Hosseini MA, Bakhshi E. The relationship between organizational citizenship behavior and organizational commitment in welfare staff (Tehran 2013). Arch Rehabil. 2015;16:18-25.

24. Kelbiso L, Belay A, Woldie M. Determinants of quality of work life among nurses working in Hawassa town public health facilities, South Ethiopia: a cross-sectional study. Nurs Res Pract. 2017;2017.

25. Almalki MJ, FitzGerald G, Clark M. Quality of work life among primary health care nurses in the Jazan region, Saudi Arabia: a cross-sectional study. Hum Resour Health. 2012;10:30. 
26. Sakkaki M, Hajimiri K, Farsi F. Quality of work life among midwives working in Zanjan University of Medical Sciences Hospitals. PCNM. 2013;2:41-48.

27. Lorber M, Treven S, Mumel D. Leaders' behavior in association with job satisfaction and organizational commitment. Social Issues in the Workplace: Breakthroughs in Research and Practice: IGI Global; 2018:602-624.

28. Ghiyasvandian S, Sedighiyani A, Kazemnejad A, Iranshahi I. Relationship between organizational communication satisfaction and organizational commitment in nurses. Iran J Med Ethics Hist Med. 2017;9:20-33

29. Abbaszadeh A, Borhani F, Sadat Seydghibi F, Shokoohi M. Organizational commitment and its aspect in nurses in Hospitals of Shiraz University of Medical Science. J Med Ethics. 2013;7:33-46.

30. Ansari M, Bagheri A, Salehi M. Organizational commitment from theorists view and the strategic role of human resource management practices (Hrmp) in its improvement. Police Hum Dev. 2010;7:35-72.

31. Veličković VM, Višnjić $A$, Jović $S$, et al. Organizational commitment and job satisfaction among nurses in Serbia: a factor analysis. Nurs Outlook 2014;62:415-427.

32. Roohi G, Asayesh $\mathrm{H}$, Rahmani $\mathrm{H}$, Abbasi A. The relationship job satisfaction and organizational commitment of nurses in hospitals of Golestan University of Medical Sciences. J Payesh. 2011;10:285-292.

33. Ebadi A, Nehrir B, Toufighi S, Karimizarchi A, Honarvar $\mathrm{H}$. Relationship of job satisfaction and organizational commitment in hospital nurses. J Mil Med. 2010;12:23-26.

34. Delgoshaei B, Tofighi S, Kermani B. The relationship between organizational climate and organizational commitment in teaching hospitals of Hamedan University of medical sciences. Q Horiz Med Sci. 2009;14:60-68.

35. Eren H, Hisar F. Quality of work life perceived by nurses and their organizational commitment level. J Hum Sci. 2016;13:1123-1132.

36. Hashempour R, Hosseinpour Ghahremanlou H, Etemadi S, Poursadeghiyan $M$. The relationship between quality of work life and organizational commitment of Iranian emergency nurses. Health Emerg Disasters. 2018;4:49-54. 